escritito porn...

'José Daniel Carabajal

Licenciado en Sociología, investigador del Centro de Investigaciones

Jurídicas y Sociales de la Universidad Nacional de Córdoba, Argentina.

\jdc_sgo@hotmail.com

(D) ORCID ID https://orcid.org/0000-0002-3649-2890

Cómo citar / citation:

Carabajal, J. D. (2020). ¿Trabajar o no trabajar? Esa es la cuestión. Un cuestionamiento sobre las dificultades en la inserción laboral de algunas personas con discapacidad en Santiago del Estero, Argentina. Voces desde

el Trabajo Social, 8(1), 66-87 https://doi.org/10.31919/voces.v8i1.230.

Recibido / received: 22 de agosto de 2020
Revisado / reviewed: 25 de noviembre de 2020
Aceptado / accepted: 22 de enero de 2021

Derechos de autoría / Copyright: (C) 2020 Carabajal, J. D. Este es un artículo de acceso abierto y distribuido bajo los términos de la licencia y políticas de Creative Commons Attribution 4.0 International License. 


\title{
¿TRABAJAR O NO TRABAJAR? ESA ES LA CUESTIÓN. UN CUESTIONAMIENTO SOBRE LAS DIFICULTADES EN LA INSERCIÓN LABORAL DE ALGUNAS PERSONAS CON DISCAPACIDAD EN SANTIAGO DEL ESTERO, ARGENTINA
}

\author{
escrito por of \\ José Daniel Carabajal ${ }^{1}$ (D) \\ fopenaccess PeER-ReVUEWed
}

\section{Resumen}

En este artículo se analizará la problemática concerniente a la discapacidad y la dimensión laboral, partiendo de la premisa de las falencias en cuanto a la inclusión laboral. Para ello se tendrá en cuenta la legislación vigente y la teoría al respecto de esta problemática tan antigua como actual. Lamentablemente, parecen no alcanzar las legislaciones y políticas públicas desplegadas por el Estado, si es este mismo Estado quien no cumple sus propias normativas. El Estado pone en una encrucijada tal a las personas con discapacidad que no solo parece vulnerar sus derechos sino también de la propia importancia del desarrollo personal, profesional y laboral de las personas con discapacidad. Este reconocimiento es básico para entender que las personas con discapacidad tienen derecho a casarse, a tener propiedades, a trabajar y no por ello dejar de ser discapacitados, y pueden valerse por sí mismos en la medida de sus posibilidades. 


\section{Descriptores}

discapacidad, trabajo, inclusión, Santiago del Estero, Argentina

\section{Sumario}

Introducción. Referentes conceptuales. Metodología. Resultados. Conclusión.

\section{[EN] TO WORK OR NOT TO WORK? THAT IS THE QUESTION. A QUESTIONING ABOUT THE DIFFICULTIES IN THE LABOR INSERTION OF SOME PEOPLE WITH DISABILITIES IN SANTIAGO DEL ESTERO, ARGENTINA}

\section{Abstract}

In this article, the problem concerning disability and the labor dimension will be analyzed, starting from the premise of shortcomings in terms of labor inclusion. For this, the current legislation and the theory regarding this problem as old as current will be taken into account. Unfortunately, the laws and public policies deployed by the State do not seem to reach if it is this same State that does not comply with its own regulations. The State puts people with disabilities at such a crossroads that it not only seems to violate their rights but also the very importance of the personal, professional and work development of people with disabilities. This recognition is essential to understand that people with disabilities have the right to marry, to own property, to work and not for this reason to stop being disabled, and they can fend for themselves to the best of their ability.

\section{Keywords}

disability, work, inclusion, Santiago del Estero, Argentina 


\section{Introducción}

Durante mucho tiempo se ha tratado a la discapacidad como una situación problemática, es decir una realidad no deseada que se debe revertir. Es notable como cada día aumenta más la cantidad de personas con discapacidad merced a diversas situaciones tales como accidentes de tránsito, accidentes laborales, enfermedades relacionadas con la obesidad y el sedentarismo, enfermedades vinculadas a deficiencias cardíacas, ACV, malformaciones derivadas del uso de agroquímicos, etcétera. Todo esto sin considerar las discapacidades de nacimiento, genéticas, o las producidas durante el parto y que acompañarán a la persona durante toda su vida y que, en casos extremos, no podrá ingresar al mercado laboral. Todas estas situaciones se agravan si las mismas se producen en el ámbito laboral, puesto que en el mejor de los casos la persona sufrirá un desempleo temporal hasta rehabilitar sus capacidades laborales a un nivel que le permita desempeñarse con normalidad en sus tareas cotidianas. Desde el Estado nacional se hicieron esfuerzos en el área de las políticas sociales, legislación, pactos internacionales, exenciones impositivas, capacitaciones, políticas laborales, políticas públicas, buscando atenuar la problemática de las personas con discapacidad, sin embargo, estas políticas se ven confrontadas o contrapuestas en su intencionalidad. Para dar un ejemplo, se puede mencionar que mientras se desarrollan talleres y cursos para favorecer la salida laboral de personas con discapacidad, por otro lado, se quitan las pensiones otorgadas a las personas con discapacidad que trabajan, sin tener en cuenta que dichas pensiones son de carácter compensatorias y no supletorias. Es decir, en muchos casos se toma a las políticas sociales del sector como un subsidio de desempleo, lo cual no debería ser así, puesto que existen muchas personas con discapacidad que se encuentran en condiciones de trabajar y no por ello deberían perder su pensión, la cual no es una dadiva, sino una prestación que se otorga a una persona para ayudarla a paliar y compensar sus dificultades y necesidades.

\section{Referentes conceptuales}

A lo largo de la historia el concepto de discapacidad fue evolucionando y con ello la forma en que los gobiernos afrontaron las políticas públicas necesarias para dar respuesta a la problemática. Actualmente, la mayor parte de la población tomó conciencia de dicha problemática y, en consecuencia, no solo los gobiernos tomaron medidas al respecto, sino que también las 
empresas, organizaciones no gubernamentales y demás actores sociales (Puga, Peschard Mariscal, Castro, 2007) comprometidos con la problemática.

Una de las primeras concepciones sobre la discapacidad se denominó "modelo demonológico" (INDEC, 2018). Este modelo tenía fuertes bases en creencias religiosas por las cuales la discapacidad era tratada como una cuestión pecaminosa expiatoria o purgatoria por pecados cometidos por familiares. Este modelo tuvo prácticas que iban desde el infanticidio (griegos y romanos arrojaban desde los acantilados a los nacidos con alguna malformación), como así también la eliminación y el aislamiento de los afectados (Ferrante, 2015), porque es "su alteración simbólica que exige que se lo aparte o se lo ponga a prueba" (Le Breton, 2017, p. 22).

Esta concepción evolucionó y a partir de los siglos XVII y XVIII la problemática fue conceptualizada como "medico organicista biologicista" (INDEC, 2018). A partir de este nuevo abordaje la problemática fue tratada, no ya como un fenómeno espiritual o metafísico, sino más bien como una enfermedad que debía curarse o tratarse desde los parámetros y métodos de la medicina. En la actualidad se conoce que la discapacidad no se cura porque no es una patología, es una condición presente en la persona la cual puede ser mejorada, no solamente desde lo médico, sino desde lo social, educacional, legal, etcétera. Esta perspectiva tuvo su correlato moderno en la teorización de Goffman (1970/1986) cuando se refiere al estigma como una marca corporal que genera rechazo social. Esta concepción basada en el rechazo de lo diferente o distinto sigue siendo la base social de los prejuicios que actualmente existen hacia la discapacidad, dado que “Las reacciones en relación a él tejen una sutil jerarquía del espanto. Se las clasifica según el índice de excepción de las normas sobre la apariencia física." (Le Breton, 2017, p. 35).

Tanto en el modelo demonológico como en este último el problema estaba inserto en la persona que lo portaba, es decir era el individuo quien caía en desgracia, la discapacidad estaba incrustada en el individuo, y por tanto no podía valerse por sí mismo y debía ser asistido o curado por la Iglesia, los médicos, o el Estado. Estos modelos tenían una perspectiva individualista de la problemática, como si de un problema ontológico se tratara. El ser discapacitado, solo y aislado en su propia "desgracia" (Abberley, 1998). 
Tal como comentan Ferreira y Rodríguez Caamaño:

En este caso, el problema teórico se deriva de la primacía de una interpretación errónea de la discapacidad, según la cual ésta sería una «insuficiencia» atribuible en exclusiva a la persona discapacitada. Cuando lo cierto, sin embargo, es que discapacidad es un término o concepto que adquiere un sentido eminentemente cultural, y que como tal, depende del sentido asignado a otros conceptos culturalmente próximos, fundamentalmente a la idea que se nos impone de «normalidad». Dicho de otra forma, la discapacidad no es una característica objetiva aplicable a la persona, sino una construcción interpretativa inscrita en una cultura en la cual, en virtud de su particular modo de definir lo «normal», la discapacidad sería una desviación de dicha norma, una deficiencia, y como tal, reducible al caso particular de la persona concreta que la «padece». (2006, s/n)

Este paradigma con el tiempo cambió y la temática comenzó a ser vista bajo el prisma del "modelo social" (INDEC, 2018). Esta nueva perspectiva incluía dentro de la problemática, no solo al individuo, sino también al entorno físico, las relaciones sociales y familiares, $y$ todo su entorno social que incluiría al propio Estado y demás agentes, no ya como entes externos a la problemática, sino como involucrados dentro de la situación y de la solución que debía ser medida y controlada por los demás agentes intervinientes.

Tal como interpreta Le Breton:

La deficiencia impone en muchos casos una limitación en las actividades y los desplazamientos, debido a la vez a las cualidades particulares del cuerpo, pero también por causa de espacios públicos a menudo poco propicios a recibirla o instalaciones comunitarias, privadas $\mathrm{o}$ públicas, no acondicionadas para acogerla. (2017, p. 24)

Esto significa que ya el problema no está solo en el individuo sino también en el medio ambiente, en lo institucional, y en lo social. Puesto que el entorno también es quien provoca o produce esas discapacidades (accidentes de tránsito, malformaciones derivadas de productos químicos, trastornos alimenticios, etcétera). "el modelo social entiende la discapacidad como el resultado del fracaso de la sociedad al adaptarse a las necesidades de las personas discapacitadas" (Abberley, 1998, p. 78)

Hasta que, en la actualidad, se adoptó una visión más global, integral e incluyente al respecto y se la conceptualizó como "modelo biopsico-social" (INDEC, 2018). Este modelo continuó y aumentó la visión global de lo social a lo cual añade lo biológico y lo psicológico, logrando de este modo una perspectiva transversal de la problemática. 
Este modelo quita la problemática fuera del sujeto y la coloca en el medio físico y social que lo rodea, puesto que "El cuerpo deficiente es también un cuerpo a domesticar, a ajustar a un mundo físico y social que siembra mil obstáculos en su camino" (Le Breton, 2017, p. 23). En tal sentido, podría decirse que es el entorno el discapacitante, quien limita a la persona, puesto que la discapacidad no es considerada como algo inherente o inmanente al sujeto, sino que es la sociedad en su conjunto quien categoriza, según estándares de diferenciación, a las personas como discapacitada, y es esta misma sociedad la que tiene la responsabilidad de no hacer sentir discapacitado al sujeto y brindar las respuestas necesarias para que así suceda.

A base a este nuevo paradigma surgieron nuevas conceptualizaciones, de las cuales se analizará dos conceptos por considerárselos representativos de este nuevo enfoque. El primero de ellos es el elaborado por la Organización Mundial de la Salud (2001) en su "Clasificación Internacional del Funcionamiento, de la Discapacidad y de la Salud" (C.I.F.) y define que la "Discapacidad es un término genérico que incluye déficits, limitaciones en la actividad y restricciones en la participación. Indica los aspectos negativos de la interacción entre un individuo (con una "condición de salud") y sus factores contextuales (factores ambientales y personales)" (p. 206).

Asimismo, la Organización de Naciones Unidas, en el año 2007, reunió a sus países miembros en lo que se denominó "Convención sobre los derechos de las personas con discapacidad y protocolo facultativo" y que fuera ratificada por Argentina en el año 2008, por lo cual todas sus declaraciones tienen rango constitucional. Dentro de dicha convención se refiere a la persona con discapacidad como "a aquellas que tengan deficiencias físicas, mentales, intelectuales o sensoriales a largo plazo que, al interactuar con diversas barreras, puedan impedir su participación plena y efectiva en la sociedad, en igualdad de condiciones con las demás" (Naciones Unidas, 2007, p. 4).

Todo este entramado normativo supranacional (que revierte en intranacional), dio origen a lo que se denomina el "paradigma de los Derechos Humanos" (Ferrante, 2015). Esta definición se encuentra dentro del paradigma bio-psicosocial, puesto que en la primera parte del concepto se refiere a factores internos de la persona (deficiencias físicas, mentales, intelectuales, etcétera); no obstante, estos factores solo se vuelven discapacitantes en 
tanto y en cuanto existen barreras que imposibiliten a la persona su normal desempeño en su vida cotidiana. Como puede observarse la concepción de discapacidad como problemática (primero individual y luego social) tuvo su evolución y es de suponerse que tendrá nuevas redefiniciones en el futuro, de modo que el concepto se vuelve dinámico y adaptativo en sentido amplio en función de la concientización que las sociedades tomen respecto de la problemática. Por lo cual, se juzga de suma importancia crear conciencia social en todos los ámbitos posibles para continuar avanzando en definiciones cada vez más completas y abarcadoras de la realidad de las personas con discapacidad.

Desde la sociología también se mostró preocupación por la temática cuando Goffman (1970/1986) escribió su libro Estigma, en el cual describió las peripecias de una joven desfigurada cuya lesión la apartaba de la vida social. Goffman (1970/1986) definió al estigma como marcas que impiden a la persona su plena aceptación en la vida social, lo cual engloba la aceptación en el mercado laboral, lo cual es compartido por Le Breton, quien acota que "El estigma no es una naturaleza que le impone su infortunio al actor, es un añadido social en el corazón de una relación, una significación y un valor depositados desde afuera sobre un rasgo físico" (2017, p. 29).

Goffman establece tres tipos de estigmas, en primer lugar, describe "las abominaciones del cuerpo" (1970/1986, p. 14); las cuales están ligadas a deformaciones físicas muy notorias que podrían configurar discapacidades severas e invalidantes. El segundo tipo de estigma que el autor menciona son "los defectos del carácter del individuo" (Goffman, 1970/1986, p. 14) los cuales se encuentran asociados a perturbaciones mentales, vicios, adicciones, etcétera, que en algunos casos pueden ser consecuencia de las abominaciones como en el caso del desempleo (Goffman, 1970/1986, p. 14), y el tercer tipo de estigma refiere a cuestiones raciales, étnicos, etcétera, que podría ser un agravante de los otros dos.

Al respecto Le Breton (2017) aporta lo siguiente:

El estigma endurece la imposición de estatus en un sentido socialmente peyorativo. Traduce la imposibilidad del actor de desprenderse de la imagen que lleva pegada a la piel. Es definido inmediatamente por los demás de acuerdo al signo de oprobio que enarbola a su pesar. El estigma es una marca física o moral susceptible de acarrear el descrédito a un individuo que pierde entonces su estatus de persona de pleno derecho. No es una sustancia, un 
atributo objetivo, sino un juicio de valor que le impone su infortunio al individuo, una significación y un valor depositados desde afuera sobre un rasgo físico o moral (p. 30).

Todoesto constituyeunentramado de significantes, creencias y mitos sobre las personas con estigmas, entre ellos el más común es el que niega la completitud del ser humano estigmatizado (Goffman, 1970/1986), siempre faltará algo, nunca alcanzará la confiabilidad plena que se requiere para ser un miembro activo en la sociedad, siempre será relegado.

El trabajo de Goffman es mucho más extenso que los conceptos aquí vertidos, pero se considera suficiente para ilustrar la perspectiva que pudo haber tenido Goffman sobre la discapacidad. No se debe olvidar que el autor recurre de manera más genérica a las categorías conceptuales de normal y anormal, de lo cual debe deducirse que la discapacidad es una de las tantas anormalidades que Goffman refiere en su estudio.

\section{Metodología}

El propósito fue realizar una indagación, mediante entrevistas en profundidad (Rodríguez Gómez, Gil Flores, y García Jiménez, 1999), sobre la problemática de la discapacidad en relación con la inserción de personas con discapacidad al mercado laboral de la provincia de Santiago del Estero en Argentina. El intento cognitivo se dirigió a las motivaciones, prácticas y experiencias de los actores involucrados en la temática en estudio, se realizó un abordaje a partir de una estrategia metodológica cualitativa (Pineda, De Alvarado, \& De Canales, 1994). Se utilizó como herramientas para la recolección de datos primarios las entrevistas en profundidad, y entrevistas a informantes claves. Se trabajó con un esquema (un listado de entrevistados) para seleccionarlos de acuerdo con una determinada característica. Se tomó un mínimo de seis entrevistados relacionados con el tema que se pretende estudiar (personas con discapacidad, docentes de educación especial, familiares de personas con discapacidad, etcétera). La intención de esta estrategia fue "poner en tensión los relatos" para poder contrastarlos y poder compararlos, $\mathrm{y}$ de este modo hallar similitudes y diferencias, concordancias y/o contradicciones entre los diferentes entrevistados entre sí, como así también con lo reflejado por los medios de comunicación escritos y diferentes publicaciones. Dichas entrevistas se realizaron con el total consentimiento de los mismos y se adulteró sus nombres para resguardar su identidad. Se utilizó bibliografía de autores que se refieran a la temática, 
documentos oficiales elaborados por organismos transnacionales (O.N.U., O.M.S.,); material estadístico del INDEC, fuentes periodísticas, de fundaciones, asociaciones, etcétera. Para la obtención y relevamiento de información secundaria se recurrió a libros, documentos, archivos, revistas y la exploración de páginas Web en la red Internet. Asimismo, como fuentes secundarias de datos, se recurrió a los diarios de mayor circulación a nivel nacional (Clarín, La Nación, Página 12, etcétera).

\section{Resultados}

\section{Capacitación y discapacidad}

La formación general posibilita al sujeto con necesidades educativas especiales, ser miembro activo de la comunidad y acceder a una capacitación especializada que le permita integrarse laboralmente según sus posibilidades, habilidades y saberes. Para que esto sea posible la formación debe tener en cuenta todos los ejes, los campos y su entrecruzamiento, formación en ciencias básicas, más formación especializada, formación general y formación especializada más intereses personales, práctica profesional, conocimientos sobre las necesidades de la comunidad y lo que la comunidad espera de él, etcétera. Todo lo cual redundará en aprendizaje y servicio, solidaridad, desempeño cooperativo de las personas con discapacidad (Froles \& Fiamberti, 2008).

Al respecto se puede reflexionar que todos somos seres, es decir ya somos, lo que no todos podemos es hacer todo, pero todos los seres humanos tienen capacidades que merecen ser detectadas $y$ desarrolladas. Desde la educación superior, pero más específicamente desde las universidades, tanto estatales como privadas, se vienen realizando esfuerzos valiosos en aras de la integración de las personas con discapacidad a su alumnado (entrega de PC, rampas, aulas accesibles, capacitación del personal, charlas, congresos y seminarios sobre la temática, etcétera) y en algunos casos se incorpora profesores con discapacidad. Hasta aquí las buenas intenciones son perfectamente validas, se capacita a los alumnos y futuros egresados para desempeñarse profesionalmente en el mercado laboral, pero una vez egresado el alumno queda sin contención ni académica ni laboral, puesto que "Mientras que en las relaciones sociales cualquier individuo puede reclamar un crédito de confianza a su favor, el afectado por una deficiencia física, mental o sensorial está gravado con una carga negativa que hace difícil su aproximación" (Le Breton, 2017, p. 
27), lo cual dificulta las posibilidades de ingresar al campo laboral de manera exitosa.

En palabras de Javier Lioy:

Cuando comienzan a ser reconocidas, la problemática pasa por los prejuicios instalados. Muchas veces, el proceso de incorporación es por un diagnóstico y no por una capacidad. Entonces, esto obliga a la organización a tomar una serie de actividades, requisitos y esfuerzos para algo que, en general, no están preparadas (Bucari, 2018).

Nosotros en la escuela tenemos dos proyectos del que participan los alumnos, uno que es el de bolsitas, para los alumnos que no pueden realizar tareas en la cocina, y otro el de fábrica de dulces y mermeladas para los alumnos que no van a correr riesgos de quemarse o cosas así, pero tratamos de darle a todos la posibilidad de que hagan algo dentro de la escuela, que se vayan capacitando y puedan tener un ingreso. (Entrevista con María, docente de educación especial. Realizada el 15/04/2020)

También es necesario resaltar que los procesos de educación, capacitación y desarrollo de un individuo solo se hacen posibles cuando se tiene la oportunidad de acceder a dichos servicios educativos y formativos, puesto que en algunos casos es complicada la asistencia y permanencia dentro del sistema educativo común de las personas con discapacidad.
Por lo tanto se debe propender a la promoción de la persona humana capacitándola y haciéndola actora de su propia realidad, modificando el eje de la acción social desde un paradigma puramente asistencialista hacia un paradigma de construcción social de su propia realidad, dándole de esta manera la oportunidad de crecer independientemente de la acción social desplegada por el sistema estatal y generando, de esta manera, su propio sustento; lo cual redundará en una elevación de la autopercepción de sus propias capacidades y del trabajo como fuente de dignidad del ser humano.

Los mismos autores (Froles \& Fiamberti, 2008) argumentan que:

La escasez de recursos económicos de quienes se encuentran desocupados y dependientes de su entorno y la pauperización del valor de las pensiones y jubilaciones limitan seriamente la posibilidad de sostener un proceso educativo, que en algunos casos requiere gastos de transporte y materiales de estudio especiales, etc. En definitiva, el costo de oportunidad que implica la elección de estudiar constituye para un adulto un obstáculo económico muy difícil de superar (p. 167).

Por esta misma razón es que se debe brindar una capacitación dentro del mismo centro educativo, de modo tal que no sean dos procesos separados, por un lado, educación 
y por otro lado capacitación. Tomar esta perspectiva integral exigirá de las universidades desarrollar programas orientados al área que contemplen pasantías y cursos de primer empleo o similares. Se estima que de esta manera se evitaría el gasto y la incomodidad que genera, para las personas con capacidades diferentes, tener que buscar por sus propios medios una capacitación laboral que les permita afrontar sus necesidades básicas y permitirles crecer integralmente como personas. "En este sentido, Mazzochi remarca que hay una exigencia extra para estas personas en la búsqueda laboral, que implica superar dificultades a la hora de mostrar sus capacidades" (Bucari, 2018, párr. 7).

Desde la universidad tratamos de ayudar a los alumnos con discapacidad por medio de una comisión que se ha creado, donde nos encargamos de hablar con los profesores si hubiera algún problema, o de conseguir o mediar para conseguir aulas que sean accesibles, porque algunas aulas están arriba y algunos chicos no pueden subir entonces le tratamos de conseguir un aula abajo y le pedimos al docente que 'si por favor se puede cambiar de aula'. Otra tarea que hacemos es darles clases de apoyo o enseñarles técnicas de estudio, porque consideramos que es fundamental que se terminen sus estudios (Entrevista con Valeria, Docente universitaria. Realizada el 25/03/2020).

Por lo tanto, se debe promover la inserción laboral y de este modo mejorar la calidad de vida de las personas con discapacidad mediante su capacitación y formación, y de este modo favorecer su inserción social y laboral, como así también contribuir al mejoramiento de su situación económica pues la mayoría de las personas son de escasos recursos económicos. "El índice de desempleo de las personas con discapacidad es de un $75 \%$ y casi el $44 \%$ de esas personas son 'cabeza de hogar'" (Infobae, 2017, párr. 1). Esta dificultosa situación económica será "la punta del iceberg" de muchas otras situaciones desfavorables que se irán sucediendo en cadena, como falta de acceso a la educación, salud, obra social, etcétera. La entrega de equipos y computadoras en las universidades, no es suficiente, se deben celebrar acuerdos de pasantías, a modo de inserción laboral y reconocimiento de capacidades laborales, y compromisos de las universidades con los sectores tanto público como privado, también se debería tener en cuenta que el cupo de empleos del 4 por ciento que establece la ley nacional 25.699 se debe cumplir en la asignación de ayudantías de catedra tanto rentadas como ad honorem. 


\section{Discapacidad y trabajo}

Durante mucho tiempo se pensó que las personas con discapacidad eran personas incapaces de realizar cualquier tipo de actividad formativa y productiva, relegándolos del ámbito laboral y, por consiguiente, de su realización en el mundo del trabajo y de su propio sustento económico, solo dependientes del subsidio estatal o del mantenimiento de la familia a cargo porque "no es considerada como sujeto, es decir, en tanto oculta 'ese algo y casi nada' que le da sentido y contorno a su existencia, sino como que tiene algo que falta, lo que la aparta precisamente del lazo social ordinario" (Le Breton, 2017, p. 31).

Trabajar es una necesidad humana, no solo porque permite obtener ingresos para la subsistencia, sino porque es una fuente de desarrollo y satisfacción personales. Para trabajar, las personas deben poseer un conjunto de conocimientos, experiencias, capacidades y posibilidades, a partir de los cuales puedan identificar sus propios obstáculos y valorar sus saberes y habilidades. En tal sentido se debe considerar que las personas con discapacidad también deben tener la oportunidad de desarrollarse como personas mediante su inserción en la actividad laboral.
Ya la Constitución de la Nación Argentina garantiza el derecho del trabajo y de los trabajadores en sus artículos 14 y 14 bis, como así también dentro de las atribuciones del Congreso de la Nación se menciona en el Articulo 75, inciso 19 que dicho Congreso tiene entre sus facultades "Proveer lo conducente al desarrollo humano, al progreso económico con justicia social, a la productividad de la economía nacional, a la generación de empleo, a la formación profesional de los trabajadores"; con lo cual queda sustentado el valor del trabajo para la dignificación de la persona.

Por ello se considera la dimensión del trabajo tal como lo concibe la Organización Internacional del Trabajo (O.I.T.) según Del Mármol (2008):

El trabajo decente resume las aspiraciones de los individuos en lo que concierne a sus vidas laborales, e implica oportunidades de obtener un trabajo productivo con una remuneración justa, seguridad en el lugar de trabajo y protección social para las familias, mejores perspectivas para el desarrollo personal y la integración social, libertad para que los individuos manifiesten sus preocupaciones, se organicen y participen en la toma de aquellas decisiones que afectan a sus vidas, así como la igualdad de oportunidades y de trato para mujeres y hombres (p. 161). 
No obstante, el mercado laboral, siempre competitivo y voraz, no ofrece la tan mentada igualdad de oportunidades, dado que "Las asperezas del cuerpo o de la palabra entorpecen entonces el progreso del intercambio. El cuerpo extraño muda en cuerpo extranjero, opaco en su diferencia" (Le Breton, 2017, p. 32), puesto que siempre están presentes los prejuicios injustificados por parte de empleadores temerosos de la supuesta baja productividad o un presunto mayor ausentismo que los de personas sin discapacidades. Tal como lo afirma Infobae (2017), "El $71 \%$ de las empresas argentinas no emplea personas con discapacidad" (párr. 1), lo cual crea una brecha todavía difícil de suplir pues persisten prejuicios que se terminan convirtiendo en discriminación dado lo injustificado de sus fundamentos.

Son numerosos los desafíos para incorporarse al mercado laboral, entre ellos, prejuicios negativos sobre las capacidades profesionales de estas personas y sus logros académicos inferiores, como consecuencia de prácticas de formación excluyentes', señala Mazzochi. El resultado es que, muchas veces, ellos mismos sientan que no pueden competir (Bucari, 2018, párr. 8).

Yo era informático, hacia el mantenimiento de redes en el aeropuerto, y un día tuve un accidente en moto, si bien no perdí mis brazos, pero si perdí un ojo. Cuando me pasa eso ya no podía seguir trabajando, entonces me jubilan por invalidez y a partir de ahí nunca más pude volver a trabajar en nada, ahora tengo un almacén en mi casa, pero no es lo mismo, (...) pero duele que ya no te tengan en cuenta para nada, porque los conocimientos los sigo teniendo, pero igual, ya no soy el mismo y no te valoran de igual forma (Entrevista con Andrés, discapacitado desempleado. Realizado el 28/05/2020)

Con un mercado laboral tan exigente y un entorno social discriminatorio, se genera en ellos impotencia y desánimo muy difíciles de superar. Vivencian que ningún esfuerzo es válido, ya que de todas maneras estaría condenado al fracaso. Aparecen los argumentos del enojo que crea tanta frustración, 'para qué si igual no vamos a conseguir trabajo', quedando atrapados y paralizados en una situación dilemática, sin salida... sin la dimensión humana de forjar el futuro y el proyecto personal (del Mármol; 2008, pp.165-166).

Respaldan lo aseverado por el autor las estadísticas del diario La Nación:

Las cifras son elocuentes: para las personas con discapacidad en la Argentina, el derecho a un trabajo es uno de los más vulnerados, tanto que solo un $32,2 \%$ de esta población en edad laboral logra acceder a un empleo. Los más afectados son los jóvenes de hasta 
29 años, se trata de una situación crónica y con una marcada brecha entre hombres y mujeres" (Bucari, 2018, párr. 1).

De aquel $32,2 \%$ que consiguió ingresar al mundo laboral, el $66 \%$ se desempeña en el sector privado y el $34 \%$, en el público. El $49,4 \%$ son empleados, el $40,5 \%$ trabaja por cuenta propia, el $6,8 \%$ se ocupa en el ámbito doméstico y el 3,3\% es patrón. (Bucari, 2018, párr. 4)

Estos datos coinciden con lo que afirma Ferrante (2015):

Algunas organizaciones de personas con discapacidad estiman que un $80 \%$ de éstas en el país se ven afectadas por el desempleo, mientras que asociaciones sindicales elevan esta cifra al $91 \%$ (redi, 2013; Banco Mundial, 2014; Joly y Venturiello, 2012). Dichas cifras se ajustan a las arrojadas a nivel global por la Organización Internacional del Trabajo en 2005, que estiman que un $80 \%$ de las personas con discapacidad están afectadas por el desempleo crónico e invisibilizadas a través de la categoría inactivo (Joly y Venturiello, 2012; Joly, 2008) (p. 165).

Puede observarse como las personas con discapacidad fueron perdiendo espacios y prestaciones en aras de un economicismo cada vez menos humano. En este sentido, el trabajo debe ser considerado como una contribución a la propia valoración personal y a elevar la autoestima de los beneficiarios, colocándolos como sujetos activos de su propia transformación personal, su propio progreso, bienestar económico "y de los esfuerzos por contrarrestar la morfología y la capacidad normativa que condena o borra a personas físicamente discapacitadas" (Butler, 2006, p. 59).

...y conseguir trabajo es muy complicado, vas a buscar trabajo $y$ te miran de arriba abajo y es como si te dijeran 'aquí no hay nada para vos', o si no te dicen 'anda a la oficina de empleo ahí tal vez tengan algo para vos' una vez una mujer me dijo que vaya a una agencia de recursos humanos. Fui deje CV y hasta hoy no me llamaron jajajaja, que le vas a hacer" (Entrevista con Juan. Discapacitado y desempleado. Realizado el 20/05/2020)

Desde la normativa misma se proscribe laboralmente a las personas con discapacidad cuando en realidad la misma normativa debería prever mecanismos institucionales y legales para resguardar la seguridad social y al mismo tiempo no lesionar el derecho al trabajo consagrado en la Constitución Nacional, de ello puede interpretarse la inconstitucionalidad de tal ordenamiento administrativo en cuanto al régimen de pensiones.

Otra problemática es la incompatibilidad entre la pensión por discapacidad y el trabajo. 'La persona que es contratada pierde la pensión y entonces tiene miedo de quedarse sin nada si el trabajo no funciona', advierte Español. 
Desde su óptica, debería pensarse en un modelo que permita que el beneficio quede en stand by y que se active instantáneamente ante la pérdida del puesto. 'Sino, es un desincentivo terrible', resume (Bucari, 2018, párr. 14)

Esta situación configura una autocontradicción en sí misma, pues dentro del circulo dialectico tendríamos lumpenes proletarios con capacidad de trabajar, porque "No existen motivos médicos para que las personas con discapacidad en edad de trabajar no lo realicen, sino que la "inactividad" y el desempleo crónico (e invisibilizado) son resultado de las políticas de la discapacitación." (Ferrante, 2015, p. 165); pero condenados a vivir del Estado o de sus familias y reducidos a la inutilidad por un sistema judicial y previsional retrogrado que castiga a quienes pretenden ser trabajadores formales o encapsulando en ergástulas de formas de trabajo protegido o cual fuere la denominación del paradigma capacitista con la cual se pretende diferenciar a trabajadores que podrían, en muchos casos, hacerlo en igualdad de condiciones y sin ningún tipo de diferendo.

yo ya no busco más trabajo, me cansé de andar rogando y viéndoles la cara de lástima que te ponen algunos, yo me recibí de licenciado en economía, hice un $\mathrm{MBA}^{1}$, y lo

1 Master of Business Administration mismo no pasa nada, ya prefiero quedarme en casa con mi pensión que me dieron cuando murió mi padre, porque te das cuenta que no pasa por la capacitación, sino por la desconfianza que inspiras, creen que porque tengas un movimiento raro ya sos medio tonto, medio lerdo, y no hay título que valga para borrar esa barrera, te das cuenta que vos no sos el problema, el problema es la discriminación que te hacen (Entrevista con Hugo. Discapacitado y desempleado. Realizado el 05/06/2020)

Mientras que por un lado se otorgan exenciones impositivas y se crean talleres protegidos, por otro lado, se obliga a las personas con discapacidad a pagar impuestos por realizar actividades profesionales, 0 en el peor de los casos se les quita su pensión si en el entrecruzamiento de datos surgiere que una persona que cobra una pensión está trabajando y tributando en alguna categoría fiscal. "donde el fantasma de la vulnerabilidad atraviesa cada cuerpo y en el que las necesidades sociales son percibidas como cuestiones que ya no serán resueltas por la seguridad social" (Ferrante, 2015, p. 170). Esta actitud lejos de contribuir a la inserción laboral castiga a la persona con discapacidad que busca desarrollarse profesionalmente - laboralmente. Como si de una encrucijada perversa se tratara, se coloca a la persona con discapacidad en una dualidad insanable entre ser 
discapacitado o trabajador aportante al sistema. Este desempleo, tanto voluntario como involuntario, se ve reflejado estadísticamente porque "La tasa de inactividad entre estas personas es del $64,1 \%$ y el desempleo llega al 10,3\%, casi un punto más que a nivel general." (Bucari, 2018, párr. 2)

A dichas ambivalencias sociales se refiere Le Breton (2011):

Ambivalencia que éste experimenta en la vida cotidiana, ya que el discurso social le afirma que es un hombre normal, miembro por entero de la comunidad, que su dignidad $\mathrm{y}$ valores personales no están de ningún modo mermados por su conformación física o sus disposiciones sensoriales pero, al mismo tiempo, objetivamente es un marginal, queda más o menos fuera del mundo del trabajo, se lo asiste con ayuda social, está fuera de la vida colectiva por sus dificultades para desplazarse y por infraestructuras urbanas frecuentemente mal adaptadas" (p. 77).

Con este razonamiento se concluye que incluso las leyes mismas son "discapacitantes" en el sentido de que forman el entorno social que limita a las personas con discapacidad. Mientras que en cualquier plan social 0 de trabajo se paga a las personas para que se capaciten $o$ realicen alguna prestación laboral, a los discapacitados se les paga para no hacer nada, y si quisieran tomar la iniciativa de realizar algún trabajo se les deja de pagar algo que, por ley, y no por políticas sociales o laborales, les corresponde, porque "el cuerpo deficiente deviene un elemento que amerita ciertos beneficios focales que serán considerados una especie de compensación individual por una situación de desventaja, de la cual no se es responsable" (Ferrante, 2015, p. 159). Existe un desfasaje entre la regulación normativa y los nuevos paradigmas y postulados sobre discapacidad puesto que las normativas vigentes claramente se basan en el paradigma "médico organicista - biologicista" (INDEC, 2018).

\section{Los empleadores}

Unodelosmayores inconvenientes y barreras a la inclusión laboral es aquel mito que equipara discapacidad con algún tipo de retraso o trastorno mental que hace de una persona con discapacidad un ente incapaz de entender, razonar, comunicarse o comprender lo que se le solicita en su puesto de trabajo, sin tener en cuenta que existen discapacidades que nada tienen que ver con lo cognitivo y que solo exigen funciones motoras, como manejar una PC, atención telefónica, o atención a clientes. No obstante ello, el prejuicio se transforma en discriminación y en este momento, "la pura debilidad, 
incapacidad de resistir, vulnerabilidad del frágil y delicado cuerpo humano" (Bauman, 2005, p. 66) portador de discapacidad se transforma en incapacidad total. Por lo tanto, la "limitación actúa como anuladora de toda capacidad, extendiéndose a toda la persona, y aparece como un rasgo que define a quien la posee y que termina haciendo que en muchas ocasiones nombremos a las personas con discapacidad como 'los discapacitados'” (Eroles \& Fiamberti, 2008, p. 163).

Marcolongo explica que el contacto con los empleadores es fundamental para superar los prejuicios. 'Muchas personas nos relatan que cuando llegan a una entrevista, si van con un bastón, por ejemplo, quien los recibe lo primero que hace es mirar eso, poner el ojo en la discapacidad y no en las capacidades', detalla. Por eso, les explican a las empresas 'que tienen que buscar el mejor talento posible y que si no contratan a estas personas, están dejando afuera un $10 \%$ del mercado laboral $y$, tal vez, perdiéndote al mejor postulante'. (Bucari, 2018, párr. 10).

Al preguntarles a ese $14 \%$ por qué no contrataría personal con discapacidad, el $72 \%$ de ellos afirma que no tiene el lugar de trabajo adaptado, el $11 \%$ porque es una temática que les cuesta manejar, el 3\% por no saber dónde hacer la búsqueda, y otro $14 \%$ por no conocer las políticas de inclusión (Infobae, 2017, párr. 7).
No nunca ocupé una persona con discapacidad, ojo, no quiero decir con esto que no la ocuparía, habría que ver si su discapacidad da para el perfil que queremos en la empresa, pero sí, seguramente que si ocuparía (Entrevista con Juan José. Dueño de comercio dedicado al rubro electrodomésticos. Realizado el 10/06/2020).

Esta falta de conciencia por parte de los empleadores, tanto privado como público, puede explicarse por lo que mientras para la persona con discapacidad "todo encuentro es una nueva prueba, provoca una duda sobre cómo será recibido y aceptado por el otro en su dignidad. El actor que dispone de su integridad física tiene una tendencia a evitar provocarse un malestar desagradable" (Le Breton, 2011, p. 78), las personas sin discapacidad no tienen que pasar por ese doble filtro de selección, es decir ya fue catalogado como capaz, mientras que una persona con discapacidad tiene que pasar la prueba de ser elegible en primera instancia y luego se pondrá a priori su incapacidad deducida de su discapacidad. Esto que ocurre en el ámbito laboral de la selección del personal ocurre como un traslado de la matriz de pensamiento social que ya se trae "sedimentado" (Berger \& Luckmann, 1968/2003) porque "Nuestras sociedades occidentales hacen de la 'discapacidad' un estigma, es decir, 
un motivo de evaluación negativa de la persona. Por otra parte, se habla de 'discapacitado', como si en su esencia de hombre estuviera el ser un 'discapacitado' más que el 'tener' una discapacidad" (Le Breton, 2011, p. 77).

Tal vez lo que más produce dudas, es si no va a ser... como decirlo... una carga para sus compañeros de trabajo, no sé. O tal vez no saber si va a necesitar una atención especial, pero te vuelvo a repetir no sé, tendríamos que evaluarlo y hablarlo con el postulante, quizás no sea para vendedor, pero si para administrativo, no sé; nunca me he planteado y como te digo tendría que ver en el momento (Entrevista con Juan José. Dueño de comercio dedicado al rubro electrodomésticos. Realizado el 10/06/2020).

Si en definitiva el trabajo dignifica al hombre, con estos esquemas institucionales y legales se les estaría negando la posibilidad de desarrollarse como personas, como seres humanos, en definitiva, se estaría creando una "exclusión de la producción social” (Abberley, 1998: 87). Se le estaría restando una parte de su humanidad, porque se estaría limitando una persona que merece desarrollarse y sentirse orgulloso de sus propios méritos y logros "Pero la mirada de los otros es otro limite" (Le Breton, 2017, p. 21), por condenarlo al ostracismo laboral, a lo que Le
Breton explica, en referencia a la discapacidad como estigma, que "El estigma asociado a la discapacidad, en particular si es visible, lo deja pegado a una identidad restrictiva y desgraciada de la que no logra escapar a pesar de sus esfuerzos y su buena voluntad." (p. 30).

\section{Conclusión}

Es notable como la sociedad ha adquirido mayor conciencia sobre la problemática, pero desgraciadamenteesamayor toma de conciencia no se traduce en mayores derechos, ni reconocimientos. Al contrario, parece operar una suerte de trueque leonino donde se cambia menos servicios por mínimas obras públicas para los discapacitados. Se ha tomado conciencia sobre las rampas para discapacitados, pero no sobre los servicios y derechos que les corresponden. ¿Será solo falta de conciencia o más bien será una falta de compromiso? En este caso la ecuación parece ser menos por menos y no más por más. Se fueron perdiendo espacios invisibles de servicio y se fueron "ganando" espacios visibles de reconocimiento. Pero ese reconocimiento es solo gestual, hay un gesto de hacer rampas y demás, y... ¿eso es todo? ¿se les reconoce realmente un espacio en nuestra sociedad? Reconocerles un espacio significa abrirles las posibilidades como a 
cualquier otra persona, por ejemplo, el derecho a trabajar, a ejercer un comercio con todas las exenciones impositivas que las leyes nacionales les garantizan. No es un pedido menor, si decimos que el trabajo dignifica a la persona, ¿Por qué no darles la oportunidad de que trabajen como personas dignas? ¿Cuándo se cumplirá en todas las reparticiones públicas el cupo de empleados discapacitados? Solo es del $4 \%$ ese cupo ¿es mucho pedir? ¿O somos tan insensibles como sociedad que solo mediante la vía judicial podemos cumplir las leyes? ¿Será acaso una falta de conocimiento de sus derechos como discapacitados? Derechos humanos son derechos naturales, no hace falta que se los conozca para cumplirlos, debe nacer de la misma naturaleza del hombre el cumplimiento, por las dudas hagamos que todos los conozcan y para que los discapacitados sepan lo que les corresponde, y los funcionarios públicos (incapacitados para tomar decisiones de cambio en nuestra sociedad) sepan que hay personas que tienen derechos aun no plenamente reconocidos. Es necesario que el marco legal acompañe al impositivo y al previsional social, pero también se requiere un rol más proactivo por parte del Estado, quien debería ser el primero en cumplir el cupo del $4 \%$ asegurado por la Ley 25.689.
Con respeto al mercado laboral, la oferta de puestos de trabajo debe ser integrada, este debe brindar mayores oportunidades a personas con alguna deficiencia o discapacidad y no exigir tramposamente competencias fuera de sus capacidades, para ello se requiere empresas respetuosas del ser humano y de la legalidad, pues cada vez más las empresas demandan mayor carga de trabajo y más funciones a cubrir por los empleados. Parece que en ese campo también el Estado ha perdido espacios, y cuando el poder público pierde espacios la ciudadanía pierde derechos y cuando la ciudadanía pierde derechos los más afectados son los que menos posibilidades tienen, en tal sentido debemos propender a un Estado fuerte que sea capaz de hacer cumplir y cumplir el mismo las leyes dictadas por sus órganos. Que el Estado de ejemplo parece un primer paso indispensable pero también es necesario revisar legislaciones que se condecían con otros paradigmas perimidos pero que aún perduran en leyes totalmente desfasadas con la realidad y los nuevos paradigmas. 


\section{Referencias}

Abberley, P. (1998). Trabajo, utopía e insuficiencia, en Discapacidad y sociedad. En L. Barton. Morata.

Bauman, Z. (2005) Vidas desperdiciadas. La modernidad y sus parias. Paidos

Berger, P.; y Luckmann T. (1968/2003) La construcción social de la realidad (1 ed.). Amorrortu.

Bucari, E. (3 de diciembre de 2018). Discapacidad: el derecho a un trabajo es uno de los más vulnerados. La Nación. Recuperado de https://www.lanacion. com.ar/comunidad/discapacidad-derechotrabajo-es-uno-mas-vulnerados-nid2198978/

Butler, J (2006). Vida precaria. El poder del duelo y la violencia (1 ed.) Paidos.

Del Mármol, A. (2008) Discapacidad y derecho al trabajo en Los derechos de las personas con discapacidad. En C. Eroles y $\mathrm{H}$, Fiamberti. EUDEBA.

Eroles, C. \& Fiamberti, H. (Comp.). (2008). Los derechos de las personas con discapacidad. EUDEBA

Eroles, C; y Fiamberti, H.(2008). Los derechos de las personas con discapacidad. EUDEBA.
Ferrante, C. (2015) Discapacidad y mendicidad en la era de la Convención: ¿postal del pasado? Convergencia. Revista de Ciencias Sociales, 22(68) 151-176.

Ferreira, M., y Rodríguez Caamaño, M. (2006). Sociología de la discapacidad: una propuesta teórica crítica. Nómadas. Critical Journal of Social and Juridical Sciences, 13 (1).

Goffman, E. (1970/1986). Estigma. La identidad deteriorada. Amorrortu editores.

Infobae. El $71 \%$ de las empresas argentinas no emplea personas con discapacidad. (9 de agosto de 2017). Infobae. Recuperado de https://www.infobae. com/discapacidad/2017/08/09/el-71-de-lasempresas-argentinas-no-emplea-personascon-discapacidad/

Instituto Nacional de Estadísticas y Censos (INDEC). (2018). Estudio nacional sobre el perfil de las personas con discapacidad. INDEC.

Le Breton, D. (2011). La sociología del cuerpo (1ed.) Nueva Visión

Le Breton, D. (2017). El cuerpo herido. Identidades estalladas modernas. Topia. 
Naciones Unidas. (2007).

Convención sobre los derechos

de las personas con discapacidad

y protocolo facultativo. New york:

Naciones Unidas.

Organización Mundial de la

Salud. (2001). Clasificación

Internacional del Funcionamiento,

de la Discapacidad y de la Salud.

Organización Mundial de la

Salud.

Pineda, E., De Alvarado, E. \& De

Canales, F. (1994). Metodología

de la Investigación. Manual para

el desarrollo del personal de salud

( $2^{\mathrm{a}}$ ed.). OPS.

Puga Espinosa, M.; Peschard

Mariscal, J.; \& Castro Escudero,

T. (2007). Hacia la sociología (4

ed). Pearson Educación.

Rodríguez Gómez, G.; Gil Flores,

J.; \& García Jiménez, E. (1999).

Metodología de la investigación

cualitativa. Ediciones Aljibe. 